\title{
Межрегиональная социально-экономическая поляризация и разработка некоторых предложений по ее снижению (на материалах ЦФО)
}

\author{
А.О. Смолякова $\bowtie$, В.И. Тихий \\ Орловский государственный университет им. И. С. Тургенева, Российская Федерачия \\ (302026, г. Орел, ул. Комсомольская д. 95) \\ Поступила в редакиию 20.04.2019 \\ Принята к публикаичи 26.02.2020
}

\begin{abstract}
Аннотация: Цель: В статье изложены теоретические основы межрегиональной дифференциации, определена актуальность научного исследования, а также необходимость сглаживания социально-экономической дифференциации в связи с тем, что высокая дифференциация приводит к социальной напряженности в проблемных регионах и тормозит экономический рост, а очень низкая дифференциация исключает конкуренцию между регионами за ресурсы и устраняет стимулы к развитию. Материaль и методы. Было рассмотрено явление поляризации на примере субъектов Центрального федерального округа и объяснена невозможность ее полного устранения по объективным причинам. На первом этапе проведен анализ динамики ключевых показателей и сравнительная оценка потенциалов субъектов, в ходе которой были выявлены регионы-лидеры и аутсайдеры, исследован уровень межрегиональной дифференциации на основе определенных показателей, отражающих социальный и экономический аспект жизни общества. Авторами была предпринята попытка разработки механизма сглаживания социально-экономической поляризации. На втором этапе научного исследования проведено ранжирование совокупности регионов по степени социально-экономического развития на основе кластерного анализа с помощью специализированной программы Statistica. Авторами была выбрана методика, которая предполагает наличие пяти групп с различным потенциалом регионов. Результаты. Были предложены меры по устранению высокой социально-экономической дифференциации среди регионов ЦФО, выявлены возможности для экономического роста исследуемого ряда субъъектов. Bbводы. Так, например, авторами была определена недостаточность государственных мер регулирования поляризации на данный момент, а также определена необходимость регулирования на субрегиональном уровне управления. Приоритетом развития исследуемых субъектов является принятие и реализация мер социальной поддержки населения. Перспективным направлением развития социально-экономического уклада Российской Федерации является переход на качественно новый уровень - в группу развитых стран.
\end{abstract}

Ключевые слова: уровень социально-экономического развития, графический метод кластеризации, классификация регионов, асимметрия социально-экономического пространства, меры по выравниванию межрегиональных социально-экономических различий.

\section{Inter-Regional Socio-Economic Polarization and Development of Some Proposals for its Reduction (on the Materials of the Central Federal District)}

\section{A. O. Smolyakova $\bowtie$, V.I. Tikhii}

Abstract: Purpose: The article sets out the theoretical foundations of interregional differentiation, determines the relevance of scientific research, as well as the need to smooth out socio-economic differentiation due to the fact that high differentiation leads to social tension in problem areas and inhibits economic growth,

() Смолякова А. О., Тихий В.И., 2020

$\triangle$ E-mail: krupchatnikova.anastasia@yandex.ru

(c) (i) Контент доступен под лицензией Creative Commons Attribution 4.0 License.

The content is available under Creative Commons Attribution 4.0 License. 
and very low differentiation excludes competition between regions for resources and eliminates incentives for development. Methods: The phenomenon of polarization was considered on the example of the regions of the Central Federal District and the impossibility of its complete elimination for objective reasons was explained. At the first stage, an analysis of the dynamics and comparative assessment of the potential of the subjects was carried out, the level of interregional differentiation was studied on the basis of certain indicators reflecting the social and economic aspect of society. The authors attempted to develop a mechanism for smoothing socioeconomic polarization. At the second stage of the research, the aggregation of regions was ranked according to the degree of socio-economic development based on cluster analysis using the specialized program Statistica. The authors chose a technique that involves the presence of five groups with different regional potentials. Results: Based on the results obtained, measures were proposed to eliminate the high differentiation among the regions of the Central Federal District, and opportunities for economic growth of a number of subjects were identified. Conclusions: For example, the authors determined the insufficiency of state measures to regulate polarization at the moment, and also determined the need for regulation at the subregional level of government. The priority of the development of the studied subjects is the adoption and implementation of measures of social support for the population. A promising direction in the development of the socio-economic structure of the Russian Federation is the transition to a qualitatively new level - in the group of developed countries.

Key words: level of socio-economic development, graphical clustering method, classification of regions, asymmetry of socio-economic space, measures to smooth out inter-regional socio-economic differences.

\section{ВВЕДЕНИЕ}

В Российской Федерации неоднородность как социального, так и экономического пространства - это исторически сложившееся и часто встречающееся явление. На территории современной России в последнее время обострились проблемы социально-экономического неравенства за счет несовершенства региональной политики в области выравнивания уровней развития регионов [2, 5]. Это явление обостряет противоречия среди населения и чревато негативными последствиями для социальной, экономической и политической жизни государства. Поэтому возникает необходимость в сглаживании социально-экономической дифференциации [4].

Важность и острота поставленной проблемы определяет необходимость глубокого исследования влияния региональной поляризации. Разработка механизма сглаживания социально-экономической поляризации субъектов Центрального Федерального округа необходима вследствие недостаточной эффективности применяемых в настоящее время мер региональной политики по выравниванию уровней их развития.

Анализ показывает, что полное устранение межрегиональных различий невозможно по объективным причинам, поскольку определенная степень неоднородности характерна для любого современного общества и может представлять один из факторов прогресса. Цель исследования поиск путей уменьшения разрыва уровней развития между субъектами за счет «подтягивания» отстающих регионов. Актуальность такого подхода объясняется следующими причинами $[1,10]: 1)$ повышен- ные интересы субъектов региона более активно включаться в общероссийский рынок; 2) стабилизация положения отставших регионов для упрощения процесса их дальнейшего развития.

Для решения поставленной задачи необходимо в первую очередь выбрать алгоритма, на основе которого будет проведена оценка поляризационной ситуации в границах Центрального Федерального округа (ЦФО) [9].

За период 2008 по 2017 годы объем валового регионального продукта (ВРП) во всех объектах ЦФО растет. Значение ВРП на душу населения является максимальным в Москве, Московской и Белгородской областях; минимальным - в Ивановской, Брянской и Костромской областях. Разница показателя между наибольшим (Москва) и наименьшим значением (Ивановская область) составляет 6,6 раза.

Наибольшие объемы отгруженных товаров собственного производства, выполненных работ и услуг собственными силами на душу населения отмечены в Калужской, Липецкой областях и городе Москве, минимальные - в Тамбовской, Орловской, Ивановской областях. Наибольшее значение ВРП (Калужская область) в 4,7 раза превышает наименьшее значение в Тамбовской области.

Максимальный объем инвестиций в основной капитал на душу населения отмечается в городе Москва, Липецкой и Воронежской областях, а минимальный - в Ивановской, Костромской и Брянской областях. Разница между наибольшим объемом инвестиций (Москва) и наименьшим значением (Ивановская область) равен 5,4 раза. 
Межрегиональная социально-экономическая поляризация и разработка некоторых предложений по ее снижению (на материалах ЦФО)

Показатели, используемые для кластерного анализа

[Table 1. Cluster analysis indicators]

\begin{tabular}{|l|l|}
\hline $\begin{array}{l}\text { Показатели, характеризующие экономическое } \\
\text { развитие [indicators of есопотіс development] }\end{array}$ & $\begin{array}{c}\text { Показатели, характеризующие социальное } \\
\text { развитие [indicators of social development] }\end{array}$ \\
\hline $\begin{array}{l}\text { Х1 - Валовой региональный продукт на душу } \\
\text { населения, рублей; }\end{array}$ & $\begin{array}{l}\text { Х6 - Среднедушевые денежные доходы } \\
\text { населения в месяц, рублей; }\end{array}$ \\
\hline $\begin{array}{l}\text { Х2 - Объем отгруженных товаров } \\
\text { собственного производства, выполненных } \\
\text { работ и услуг собственными силами на душу } \\
\text { населения, рублей; }\end{array}$ & $\begin{array}{l}\text { Х7 - Потребительские расходы в среднем на } \\
\text { душу населения в месяц, рублей; }\end{array}$ \\
\hline $\begin{array}{l}\text { Х3 - Инвестиции в основной капитал на душу } \\
\text { населения, рублей; }\end{array}$ & Х8 - Уровень занятости, \%; \\
\hline $\begin{array}{l}\text { Х4 -Оборот розничной торговли в расчете на } \\
\text { душу населения, рублей; }\end{array}$ & Х9- Уровень безработицы, \%. \\
\hline $\begin{array}{l}\text { Х5 - Продукция сельского хозяйства на душу } \\
\text { населения, рублей; }\end{array}$ & \\
\hline
\end{tabular}

Лидерами по обороту розничной торговли на душу населения являются следующие субъекты: город Москва, Московская, Воронежская области, при этом Костромская, Владимирская и Ивановская области имеют наименьшие значения. Разница между ними составляет 1,5 раза.

По объему продукции сельского хозяйства на душу населения на первых местах находятся Белгородская, Тамбовская и Курская области. Минимальный объем зафиксирован Московской и Ивановской областях.

Представленная статистика подтверждает существенную региональную дифференциацию по уровню экономического развития среди субъектов ЦФО. Такая же ситуация характерна и для показателей социального развития [8].

Максимальное значение уровня занятости населения зафиксировано в Москве $(74,2 \%)$, минимальное - в Рязанской области $(60,8 \%)$. Разница показателя составляет 13,4 процентных пунктов.

Наибольшее значение среднедушевых месячных денежных доходов населения отмечено в городе Москва (62532 руб.), а наименьшее - во Владимирской области (23988 руб.). Максимальное значение показателя превышает в 2,6 раза наименьшее значение [3].

Существенный уровень зарегистрированной безработицы отмечен в Ярославской, Орловской и Смоленской областях, а наименьший - в городе Москва и Московской области.

\section{МАТЕРИАЛЫ И МЕТОДЫ ИССЛЕДОВАНИЯ}

Алгоритм исследования межрегиональной социально-экономической поляризации выглядит следующим образом.
I. На первом этапе выявляются наиболее сильные и слабые стороны регионов с помощью определенной методики, которая включает такие действия, как: 1) группировка ряда однотипных по выбранным критериям субъектов для обеспечения высокой сопоставимости и, как следствие, проведение более точного анализа; 2) оценка социально-экономического развития субъектов, выявление неиспользуемых возможностей экономического роста; 3) проведение кластерного анализа на основе специализированного программного обеспечения Statistica для ранжирования совокупности исследуемых субъектов по группам.

II. Разработка и реализация мер по выравниванию уровней развития субъектов, внедрение инструментов по сглаживанию поляризации. Второй этап включает следующие действия: 1) определение стратегических целей и задач для разработки предложений по ликвидации кризисных ситуаций на исследуемой территории; 2) поддержание достигнутой степени благосостояния субъектов РФ.

III. Приведение «отстающих» субъектов к среднерегиональному уровню развития.

IV. «Продвижение лидера» - поддержка «полюса» - одного или нескольких наиболее благополучных субъектов.

Результатом поэтапного исследования и внедрения мер в региональную политику будет являться уменьшение асимметрии и рост социального и экономического потенциала субъектов [12].

\section{ОБСУЖДЕНИЕ РЕЗУЛЬТАТОВ}

Для ранжирования совокупности данных по выбранным социально-экономическим показателям для субъектов Центрального Федерального 


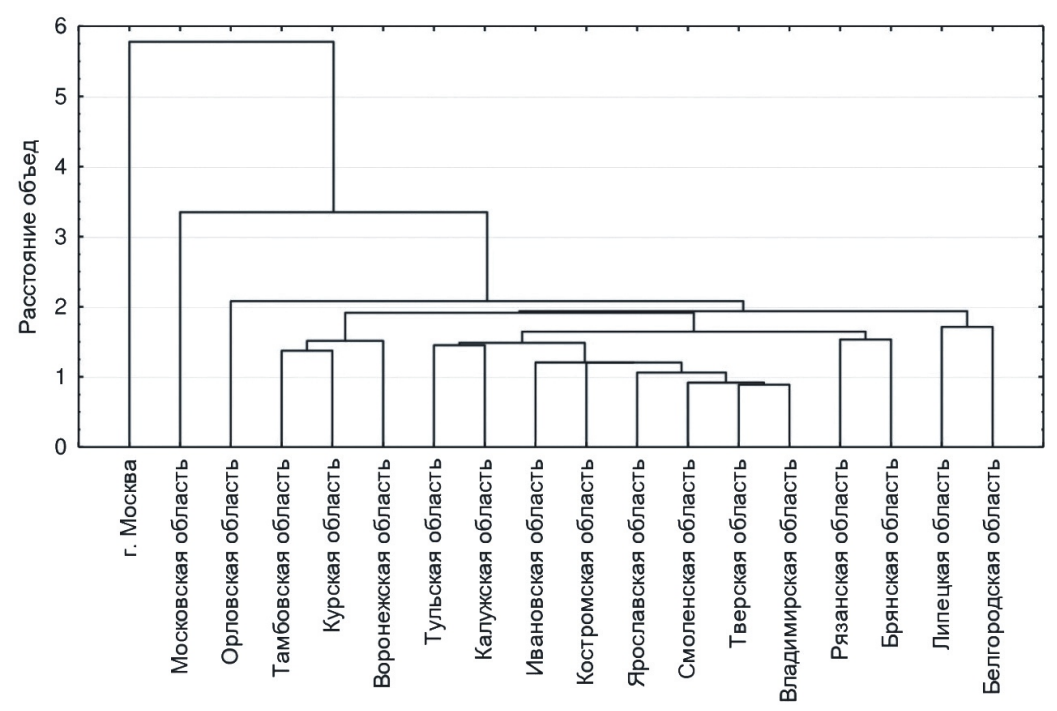

Puc. Дендрограмма, метод полной связи, евклидово расстояние [Fig. Dendrogram, full communication method, Euclidean distance]

Источник: получено на основе данных сборников - Регионы России. Основные характеристики субъектов Российской Федерации - 2018 г., Россия в цифрах - 2018 г. с помощью программы Statistica

округа проведем кластерный анализ с помощью специализированного программного обеспечения - Statistica, что в дальнейшем позволит оценить их уровень развития [7].

Наблюдения и переменные разобьем на группы, используя евклидову меру расстояния и такое правило объединения кластеров, как полная связь.

Данные для кластерного анализа содержат следующую информацию о субъектах, входящих в состав ЦФО (таблица 1):

Результатом кластерного анализа является расчленение субъектов ЦФО на классы, соответствующие определенным рисковым группам. Наблюдения из одних и тех же групп характеризуются схожими уровнями социально-экономического развития.

Метод полной связи определяет расстояние между кластерами как наибольшее расстояние между любыми двумя объектами в различных кластерах (т. е. «наиболее удаленными соседями»). Рассмотрим результаты применения графического метода ранжирования (рис.).

Кластерный анализ социально-экономического потенциала регионов ЦФО сгруппировал субъекты с учетом среднего значения расстояния до центра кластера и выявил уровень развития регионов.

В рамках исследования региональной дифференциации проведено ранжирование субъектов, а также их последующая классификация в соответ- ствии с социально-экономическим потенциалом каждого региона в ряду (таблица 2):

\section{ЗАКЛЮЧЕНИЕ}

По результатам исследования можно сделать следующие выводы.

1. Социально-экономическая поляризация определяется как длительное во времени и устойчивое по направленности выделение центра на фоне прилежащей периферии, вследствие объективной и субъективной асимметрии на данной территории, выраженное в дифференциации территории по ее социально-экономическим параметрам [11].

2. Многоаспектная и комплексная типологизация и классификация экономического пространства позволит эффективнее применять инструменты сглаживания поляризации социальных и экономических сфер жизни регионов.

3. В свете стратегии поляризованного развития очевидна необходимость определения путей сглаживания социально-экономической дифференциации на субрегиональном уровне управления [6].

4. С помощью анализа динамики социальноэкономической поляризации ЦФО была оценена поляризационная ситуация и выявлена недостаточность мер государственного регулирования по сглаживанию социально-экономической поляризации.

Главной стратегической целью внедрения на практике механизма сглаживания межрегиональной социально-экономической поляризации является повышение уровня и качества жизни населе- 
Межрегиональная социально-экономическая поляризация и разработка некоторых предложений по ее снижению (на материалах ЦФО)

Классификация регионов ЦФО по уровню развития

[Table 2. Classification of regions of the central federal district by level of development]

\begin{tabular}{|l|l|}
\hline $\begin{array}{l}\text { Регионы с уровнем развития выше } \\
\text { среднего [above average regions level of } \\
\text { development regions] }\end{array}$ & $\begin{array}{l}\text { г. Москва, Белгородская, Воронежская, Курская и } \\
\text { Тамбовская области }\end{array}$ \\
\hline $\begin{array}{l}\text { Регионы co средним уровнем развития } \\
\text { [middle level of development regions] }\end{array}$ & $\begin{array}{l}\text { Калужская, Липецкая, Московская и Тульская } \\
\text { области }\end{array}$ \\
\hline $\begin{array}{l}\text { Регионы с уровнем развития ниже } \\
\text { среднего [below the average level of } \\
\text { development regions] }\end{array}$ & $\begin{array}{l}\text { Брянская, Владимирская, Ивановская, } \\
\text { Костромская, Орловская, Рязанская, Смоленская, } \\
\text { Тверская, Ярославская области }\end{array}$ \\
\hline Регионы с низким уровнем развития [low level of development regions] \\
\hline \multicolumn{2}{|l|}{ Регионы с крайне низким уровнем развития [extremely low level of development regions] } \\
\hline
\end{tabular}

Источник: получено на основе данных сборников - Регионы России. Основные характеристики субъектов Российской Федерации - 2018 г.

ния в исследуемых регионах через создание многоукладной социально-ориентированной экономики с целью динамичного ее развития и реализации национальных интересов на мировой арене.

Приоритетными направлениями развития исследуемых субъектов является принятие и реализация мер по социальной защите граждан, по сокращению безработицы и по содействию занятости населения, поддержка малого и среднего бизнеса, содействие повышению инвестиционной привлекательности регионов, разработка программ для улучшения предпринимательского и инвестиционного климата, обеспечение условий для направленности субъектов ЦФО на высокотехнологичные и наукоемкие разработки во всех отраслях.

Перспективой для субъектов с наивысшим уровнем социально-экономического развития является сохранение достигнутого уровня, для субъектов второй и третьей группы - переход в группу более высокого порядка.

\section{СПИСОК ЛИТЕРАТУРЫ}

1. Аликаева М.В. Совершенствование управления пространственной поляризацией социально-экономического развития региона. Нальчик, издательство Кабардино-Балканского университета, 2018. 101 с.

2. Заводских А. А., Тихий В. И., Шуметов В. Г. Моделирование процессов движения населения в регионах Центрального федерального округа // Региональная экономика: теория и практика, 2017, № 4, с. 772-783.

3. Зернаева А. М. Неравенство доходов населения в России // Инновационная наука, 2016, № 5-1 (17), c. $75-78$.

4. Зубаревич Н.В. Регионы России: неравенство, кризис, модернизация. Москва, Издательство Независимого института социальной политики, 2010. 160 с.
5. Кириллов В. Б, Тихий В. И. Анализ инновационного потенциала регионов ЦФО. Материалы X Международной научно-практической конференции: «Инновационное развитие российской экономики». Москва, 2017, c. $76-80$.

6. Костенко О.В., Костенко П.Е. Неравенство доходов населения в России: уровень и тенденции изменения // Вестник Воронежского государственного университета. Серия: экономика и управление, 2018, № 2, c. 90-95.

7. Кудряшов В. С., Миндлин Ю. Б. Кластерный подход как элемент формирования национальной экономики // Современная наука: актуальные проблемы теории и практики. Серия Экономика и право, 2017, № 2, c. $19-23$.

8. Малкина М. Ю. Институциональные основы неравенства доходов в экономике // Journal of Institutional Studies, 2016, № 1, c. 100-120.

9. Россошанский А.И. Социально-экономическое неравенство населения в контексте развития социального государства современной России // Вестник НГИЭИ, 2019, № 7 (98), с. 108-117.

10. Сычева И.Н. Зарубежный опыт и российская практика решения проблем социального равновесия в обществе // Экономика и бизнес: теория и практика, 2017, № 1, c. 99-105.

11. Шкаратан О.И. Социально-экономическое неравенство в современном мире и становление новых форм социального расслоения в России // Мир России. Социология. Этнология, 2018, № 2, с. 6-35.

12. Юманова У. В. Региональная оценка социальноэкономического неравенства // Вестник Воронежского государственного университета. Сер. География. Геоэкология, 2016, № 3, с. 57-60.

\section{REFERENCES}

1. Alikaeva M. V. Sovershenstvovaniye upravleniya prostranstvennoy polyarizatsiyey sotsial'no-ekonom- 
icheskogo razvitiya regiona [Improving the management of spatial polarization of socio-economic development of the region]. Nalchik, Kabardino-Balkan University publ., 2018. 101 p. (In Russ.)

2. Zavodskikh A. A., Tikhii V. I., Shumetov V. G. Modeling of population movement processes in the regions of the Central Federal District. Regional'naya ekonomika: teoriya i praktika, 2017, no. 4, pp. 772-783. (In Russ.)

3. Zernayeva A. M. Neravenstvo dokhodov naseleniya Rossii [Income inequality of Russian population]. Innovatsionnaya nauka, 2016, no. 5-1 (17), pp. 75-78. (In Russ.)

4. Zubarevich N. V. Regiony Rossii: neravenstvo, krizis, modernizatsiya [Regions of Russia: inequality, crisis, modernization]. Moscow, Independent Institute for Social Policy publ., 2010. 160 p. (In Russ.)

5. Kirillov V.B., Tikhii V.I. Analiz innovatsionnogo potentsiala regionov TSFO [Analysis of innovative potential of regions of the Central Federal District]. Materialy $X$ Mezhdunarodnoy nauchno-prakticheskoy konferentsii: "Innovatsionnoye razvitiye rossiyskoy ekonomiki”. Moscow, 2017, pp. 76-80. (In Russ.)

6. Kostenko O. V., Kostenko P. Ye. Neravenstvo dokhodov naseleniya Rossii: uroven' i tendentsii izmeneniy [Income inequality of the Russian population: level and trends of change]. Vestnik Vestnik Voronezhskogo gosudarstvennogo universiteta. Seriya Ekonomika i upravleniye, 2018, no. 2, pp. 90-95. (In Russ.)

7. Kudryashov V.S., Mindlin Yu. B. Klasternyy podkhod kak element formirovaniya natsional'noy ekonomiki

\section{КОНФЛИКТ ИНТЕРЕСОВ}

Авторы декларируют отсутствие явных и потенциальных конфликтов интересов, связанных с публикацией настоящей статьи.

\section{Смолякова Анастасия Олеговна}

студентка 1 курса магистратуры направления подготовки 38.04.08 «Финансы и кредит» Орловского государственного университета им. И.С. Тургенева, г. Орел, Российская Федерация,

ORCID: https://orcid.org/0000-0003-2199-7447, e-mail: krupchatnikova.anastasia@yandex.ru

Тихий Владимир Иванович

кандидат географических наук, доцент, исполняющий обязанности заведующего кафедрой географии, экологии и общей биологии Орловского государственного университета им. И. С. Тургенева, г. Орел, Российская Федерация, ORCID: https://orcid.org/0000-0001-6666-588X, e-mail: tikhiivi@yandex.ru
[Cluster approach as an element of formation of national economy]. Sovremennaya nauka: aktual'nyye problemy teorii i praktiki. Seriya Ekonomika i pravo, 2017, no. 2, pp. 19-23. (In Russ.)

8. Malkina M. Yu. Institutsional'nyye osnovy neravenstva dokhodov v ekonomike [Institutional foundations of income inequality in the economy]. Vestnik institutsional'nykh issledovaniy, 2016, no. 1, pp. 100-120. (In Russ.)

9. Rossoshanskiy A. I. Sotsial'no-ekonomicheskoye neravenstvo naseleniya $\mathrm{v}$ obshchestve sovremennoy Rossii [Socio-economic inequality of population in society of modern russia]. Vestnik NGIEI, 2019, no. 7 (98). pp. 108117. (In Russ.)

10. Sycheva I. N. Resheniya problem mezhdunarodnogo ravnovesiya $\mathrm{v}$ obshchestve [Solutions to problems of international balance in society]. Ekonomika i biznes: teoriya i praktika, 2017, no. 1, pp. 99-105. (In Russ.)

11. Shkaratan O. I. Sotsial'no-ekonomicheskoye neravenstvo v sovremennom mire i stanovleniye novykh form sotsial'nogo rassloyeniya v Rossii [Socio-economic inequality in the emergence of new forms of social stratification in Russia]. Mir Rossii. Sotsiologiya. Etnologiya, 2018, no. 2, pp. 6-35. (In Russ.)

12. Yumanova U. V. Regional'naya otsenka sotsial'noekonomicheskogo neravenstva [Regional Assessment of Socio-Economic Inequality]. Vestnik Voronezhskogo gosudarstvennogo universiteta. Ser. Geografiya. Geoekologiya, 2016, no. 3, pp. 57-60. (In Russ.)

\section{CONFLICT OF INTEREST}

The authors declare no information of obvious and potential conflicts of interest related to the publication of this article.

Anastasia O. Smolyakova

1st year student of the Master's programme in the direction of preparation 38.04.08 "Finance and Credit", B. A. of the direction of training 38.03.01 "Economy" Orel State University named after I. S. Turgenev, Orel, ORCID: https://orcid.org/0000-0003-2199-7447, E-mail: krupchatnikova.anastasia@yandex.ru

Vladimir I. Tikhiy

Cand. Sci. (Geogr.), Assoc. Prof., Acting Head of the Department of Geography, Ecology and Biology, Orel State University named after I. S. Turgenev, Orel, ORCID: https://orcid.org/0000-0001-6666-588X, E-mail: tikhiivi@yandex.ru 